\title{
Elementos de artes visuais articulados com TIC no processo de ensino e aprendizagem: uma revisão da literatura
}

\author{
Nani Marques Castiglio', Jordi Tasso Melo', Clevi Elena Rapkiewicz ${ }^{2}$, Simone \\ Vacaro Fogazzi \\ ${ }^{1}$ Instituto de Artes - Universidade Federal do Rio Grande do Sul (UFRGS) \\ 2 Colégio de Aplicação - Universidade Federal do Rio Grande do Sul \\ \{nancast.nmc, jorditmelo, clevirap, simonevfogazzi\}@gmail.com
}

\begin{abstract}
The insertion of Visual Arts in education articulated with Information and Communication Technology (ICT) has broad potential. Pursuing to analyze how is such articulation in Brazil, this article presents a bibliographic survey in 5 of the main publications of computing in education over the period from 2009 to 2016. There have been localized 36 articles about the theme, over a total of almost 3 thousand. The analysis of the corpus formed by these texts, considering relevant aspects in common between them, confirmed the pedagogical character and potential of Visual Arts with help from ICT resources. Despite this, the proposed use could be considered restricted, mainly for not exploring more creative aspects of the arts.
\end{abstract}

Key-words: Visual Arts, Systematic Literature Review, ICT

Resumo. A inserção de Artes Visuais na educação de forma articulada com Tecnologias de Informação e Comunicação (TIC) possui amplo potencial. Buscando analisar como está tal articulação no Brasil, este artigo apresenta um levantamento bibliográfico em 5 das principais publicações de informática na educação no período de 2009 a 2016. Foram localizados 36 artigos tratando do tema sobre um total de quase 3 mil. A análise do corpus formado por esses textos, considerando aspectos relevantes comuns entre eles, confirmou o caráter pedagógico e o potencial das Artes Visuais com auxílio de recursos de TIC. Apesar disto, o uso proposto pode ser considerado restrito, sobretudo por não explorar aspectos mais criativos das artes.

Palavras-chave: Artes Visuais, Revisão Sistemática de Literatura, TIC

\section{Introdução: sobre o componente curricular Artes Visuais e as TIC}

$\mathrm{O}$ conhecimento em arte permite a seus produtores, seja apenas uma pessoa, seja um grupo, compreender e compilar um conjunto de ideias, emoções, conceitos, elaborandoos de maneira sensível e imagética, para que possam posteriormente ser apreciados por outras pessoas. Tanto para quem cria quanto para quem é espectador, os processos artísticos são potentes para o desenvolvimento de alteridade e sensibilidade. Este tipo de experiência torna a educação mais humanitária na medida em que, conforme escreveu Pimentel (2011, p. 767),

Sendo a arte parte integrante da cultura, sua incorporação nas escolas é uma das estratégias mais poderosas para a construção de uma cidadania multicultural, já que facilita o conhecimento e o desfrute das expressões 
VI Congresso Brasileiro de Informática na Educação (CBIE 2017)

Anais do XXVIII Simpósio Brasileiro de Informática na Educação (SBIE 2017)

artísticas de diferentes culturas, o que submerge os alunos no reconhecimento e respeito à diversidade cultural e pessoal.

A Arte faz durar (DELEUZE, 1999), mas também muda: suas linguagens, estéticas e objetivos são sempre atualizados e isso obriga a manter sempre ativo o pensamento sobre a arte na escola, sua função social, seus objetivos e outras questões orbitais, que a arte impõe aos que a ela se dedicam.

Os Parâmetros Curriculares Nacionais (BRASIL, 1998), organizados pelo Ministério da Educação, foram referência durante certo período para (re)elaborações de currículos das escolas brasileiras. No volume dedicado à Arte, está entre os objetivos gerais para o ensino desta área (p. 48) que os estudantes devem ser capazes de "experimentar e explorar as possibilidades de cada linguagem artística" ao longo do Ensino Fundamental. Entre estas linguagens artísticas estão as que competem ao componente curricular Artes Visuais. Ao delimitar o que compreende por artes visuais, o documento diz que além das formas tradicionais (pintura, escultura, desenho, gravura, objetos, cerâmica, cestaria, entalhe), consideram-se parte do campo as modalidades associadas a transformações estéticas e tecnológicas do século XX, como fotografia, moda, artes gráficas, cinema, televisão, vídeo, computação, performance, holografia, desenho industrial e arte em computador.

Ao afirmar que “(...) no mundo contemporâneo as linguagens visuais ampliamse, fazendo novas combinações e criam novas modalidades. A multimídia, a performance, o videoclipe e o museu virtual são alguns exemplos em que a imagem integra-se ao texto, som e espaço" os PCN (BRASIL, 1998, p. 63) estão exemplificando como a tecnologia pode afetar valores, atitudes e maneiras de viver e fazer arte. Recomendam ainda que os estudantes tenham acesso e interajam com tecnologias da informação e comunicação (TIC), afinal também a arte contemporânea tem sido significativamente transformada por elas.

Outro documento, os Parâmetros Curriculares Nacionais do Ensino Médio (BRASIL, 2000, p. 46), avalia que no século XX os estudantes brasileiros de Ensino Médio, em sua maioria, não puderam conhecer e produzir "manifestações artísticas como, por exemplo, cinema de animação, vídeo-arte, multimídia artística, CD-ROM artístico, dentre outras das artes audiovisuais e informáticas". Neste volume (Parte II, Área de Linguagens, Códigos e suas Tecnologias) ainda afirma ser fundamental a continuidade, no componente curricular de Arte, de "conhecimentos práticos e teóricos sobre a arte aprendidos em níveis anteriores da escola básica e em sua vida cotidiana"(p. 48). Faz parte da vida cotidiana dos alunos o uso de TIC, conforme apontado na pesquisa TIC Domicílios (CETIC, 2015), seja através do acesso à Internet em casa (cerca de 52\% dos brasileiros de qualquer faixa etária), seja através do uso intenso do celular com e sem acesso à Internet nas faixas etárias mais jovens. Está explícita nos PCNEM a proposta de uso de TIC não só relacionadas a práticas artísticas, mas também em três das dez competências principais pretendidas para a área de Linguagens, Códigos e suas Tecnologias. Nas páginas 11 e 12, o volume descreve que nos processos de ensino-aprendizagem do Ensino Médio os estudantes devem

Entender os princípios das tecnologias da comunicação e da informação, associá-las aos conhecimentos científicos, às linguagens que lhes são suporte e aos problemas que se propõem a solucionar. [...] 
VI Congresso Brasileiro de Informática na Educação (CBIE 2017)

Anais do XXVIII Simpósio Brasileiro de Informática na Educação (SBIE 2017)

Entender o impacto das tecnologias da comunicação e da informação na sua vida, nos processos de produção, no desenvolvimento do conhecimento e na vida social.[...]

Aplicar as tecnologias da comunicação e da informação na escola, no trabalho e em outros contextos relevantes para a sua vida.

Há produções acadêmicas a respeito do ensino de artes também reconhecem o potencial das tecnologias. Barbosa (2010) menciona a integração de TIC no processo de ensino e aprendizagem de arte, destacando a importância de inseri-las no desenvolvimento tanto da "recepção, o entendimento e a construção de valores das artes tecnologizadas" (p. 111) quanto na própria produção cultural dos alunos. No mesmo sentido, Martins (2007) já havia observado que os recursos da informática não só trouxeram outros desafios e possibilidades aos artistas em suas novas buscas estéticas e conceituais, mas também foram apropriados pelas já antigas instituições legitimadoras, como museus e galerias. É preciso atentar, porém, à forma como essa integração é feita. De acordo com Pimentel (2011, p. 769), deve-se pensar "até que ponto é o equipamento que determina os resultados conseguidos e até que ponto esse resultado é o pensamento artístico do autor da obra", portanto se torna essencial que os estudantes "pensem seu trabalho como sua própria produção artística, e não somente usem os recursos desses programas aleatoriamente".

Observa-se, pois, uma convergência da proposta de autoria nas Artes Visuais com a possibilidade de autoria propiciada pelas TIC atualmente. Porém, em que medida essa convergência se apresenta nas pesquisas, no Brasil, integrando TIC no processo de ensino e aprendizagem de Artes Visuais? Buscando responder a essa pergunta, este artigo apresenta um levantamento bibliográfico com base em publicações da área de Informática na Educação no Brasil nos últimos oito anos. Para tanto, este artigo está organizado em 4 seções, além da presente introdução. Na seção 2 apresentamos breve análise de revisões bibliográficas presentes nas revistas e eventos considerados para esse artigo, mostrando a ausência de revisão com foco nesse componente curricular. Na seção 3 é apresentada a metodologia utilizada. Na seção 4, é apresentado o resultado da análise dos artigos e na seção 5 são apresentadas algumas considerações finais.

\section{Trabalhos relacionados}

Uma busca por artigos relativos a Artes Visuais na base de dados scielo.br (estratégia de busca: "artes visuais") permite a recuperação de 88 artigos, porém nenhuma revisão bibliográfica. Refinando a busca, procurando por artes visuais e descritores ligados a tecnologia (informática, TIC, computador, celular, digital) recupera-se 2 artigos, sendo apenas um voltado a pesquisa integrando TIC a essa área do conhecimento (RIBEIRO, 2015), mas não se refere a educação ou ações pedagógicas.

Uma pesquisa no repositório de periódicos da CAPES usando a estratégia "artes visuais" AND TIC permite a recuperação de 16 documentos, entre teses e artigos. Somente dois deles referem-se a integração de TIC no processo educativo de Artes Visuais: i) uma dissertação de mestrado da Universidade do Porto de 2002 (SILVA, 2002) feita a partir de questionários aplicados a professores de Artes e ii) um artigo também aplicando questionários a professores desta área em uma cidade do interior do RS (ZAMPERETTI e ROSSI, 2015). No mesmo repositório a pesquisa usando os descritores "artes visuais" AND computador resulta em 75 publicações, no entanto as 
VI Congresso Brasileiro de Informática na Educação (CBIE 2017)

Anais do XXVIII Simpósio Brasileiro de Informática na Educação (SBIE 2017)

únicas duas de interesse para o tema analisado são as mesmas recuperadas com a estratégia de busca já citada.

Uma busca mais específica mostra que a comunidade que pesquisa informática na educação no Brasil recorre a Revisão Sistemática de Literatura (RSL) quando necessita delimitar o estado da arte de alguma temática de pesquisa. Foram identificadas 86 revisões sistemáticas nos últimos 5 anos nas revistas RENOTE (Revista Novas Tecnologias na Educação), RBIE (Revista Brasileira de Informática na Educação) e na Informática na Educação: Teoria \& Prática (IETP), bem como nos anais do Simpósio Brasileiro de Informática na Educação (SBIE) e do Workshop de Informática na Escola (WIE). Nenhuma delas, no entanto, refere-se à área de Artes Visuais. Apenas uma tangencia a área, ao estudar o uso da fotografia como estratégia metodológica em pesquisas com crianças (SILVA, 2016).

Portanto, não foram localizados trabalhos relacionados que apresentassem revisão bibliográfica sistemática relativa a pesquisas sobre o uso de TIC no processo de ensino e aprendizagem de Artes Visuais. A metodologia para a pesquisa feita buscando preencher essa lacuna é apresentada na próxima seção.

\section{Metodologia}

Conforme apontado na seção anterior, nos últimos 5 anos foram localizados 86 artigos de RSL nas publicações da área de informática na educação no Brasil. Nessas publicações, uma das principais metodologias utilizadas é a apresentada por Kitchenham (2007). Pode-se observar que há diferentes adaptações da metodologia conforme o contexto. Analisando as várias RSL localizadas e a proposta original de Kitchenham optou-se, para o contexto específico desta revisão, por seguir as etapas indicados por Silva, Medeiros e Aranha (2014). De acordo com estes autores (p. 693) a RSL pode ser utilizada para "extrair, catalogar, analisar e sintetizar dados de vários artigos publicados em congressos, jornais e periódicos" que abordem a temática da revisão. Para tanto foram selecionadas as principais revistas e eventos de informática na educação no Brasil, a saber: RENOTE, RBIE, IETP, SBIE e WIE. O escopo das fontes selecionadas, portanto, é nacional e interdisciplinar. Periódicos e eventos internacionais da área de informática na educação e específicos da área de educação em Artes Visuais não fazem parte do alvo deste artigo, constituindo etapa futura dessa pesquisa.

A etapa seguinte indicada pelos autores é a delimitação temporal. No caso, o período escolhido foi de 2009 a 2016. Dentro desse período, buscou-se responder a uma pergunta ampla: em que medida a pesquisa sobre integração das TIC no processo de ensino e aprendizagem de Artes Visuais aproveita o potencial de autoria de ambas (TIC $e$ Artes Visuais)? Na impossibilidade de se responder a essa pergunta de forma condizente no limite de páginas do artigo, optou-se por responder a questões parciais mais específicas, que abrem caminho para a resposta mais ampla buscada. As perguntas mais restritas de pesquisa são apresentadas na Tabela 1.

Após a delimitação temporal, procedeu-se a busca dos artigos propriamente dita. Optou-se por fazer busca manual, diretamente nos veículos de publicação, considerando-se duas limitações dos mecanismos de busca. Primeiro, que não há opção de delimitação temporal. Segundo, que a amplitude de descritores que pode remeter ao campo das Artes Visuais é muito grande, de forma que publicações de interesse da pesquisa poderiam não ser recuperadas. Foram buscados descritores como Artes 
Visuais, Artes plásticas, fotografia, imagem e outros relacionados, no título, no resumo e nas palavras-chave. Todos os artigos recuperados que atendiam aos critérios foram registrados em uma planilha. A etapa de exclusão de artigos não foi necessária, uma vez que a busca manual exaustiva permitiu a não inclusão de artigos que não eram de interesse da pesquisa. Nesta fase não foram extraídos propriamente os dados para a pesquisa, apenas armazenadas as referências. Os campos analisados (título, resumo, palavras chave) dos artigos selecionados foram revisados por uma professora com mestrado na área de Artes Visuais e mais de duas décadas de experiência em educação básica nessa área de conhecimento e por uma professora doutora e com duas décadas de experiência na área de informática na educação. Essa revisão não implicou na exclusão de nenhum dos artigos selecionados. Eventualmente, pode ter havido perda de artigo não selecionado inicialmente, o que se buscou superar parcialmente fazendo busca automática para ver se aparecia algum artigo que na seleção manual não houvesse sido selecionado. Essa providência não implicou na inclusão de mais artigos no corpus.

Tabela 1: Questões de pesquisa

\begin{tabular}{|c|c|c|}
\hline Questões & Descrição & Justificativa \\
\hline QP1 & $\begin{array}{l}\text { Em que regiões do Brasil se } \\
\text { concentram os grupos que } \\
\text { apresentam pesquisas } \\
\text { interdisciplinares de TIC nas } \\
\text { Artes Visuais? }\end{array}$ & $\begin{array}{l}\text { Essa pergunta permite identificar potenciais } \\
\text { instituições para pareceriam em pesquisas futuras } \\
\text { nessa área caso identificados grupos que exploram a } \\
\text { questão da autoria. }\end{array}$ \\
\hline QP2 & $\begin{array}{l}\text { Qual o foco das pesquisas } \\
\text { integrando TIC nas Artes Visuais } \\
\text { ? Tem buscado sido buscado o } \\
\text { desenvolvimento de softwares e } \\
\text { aplicações, tëm analisado o uso } \\
\text { pedagógico de ferramentas ou se } \\
\text { tem promovido discussões } \\
\text { conceituais a respeito de artes } \\
\text { visuais e tecnologias? }\end{array}$ & $\begin{array}{l}\text { Compreender o foco das pesquisas existentes permite } \\
\text { tanto delinear novos focos de pesquisa quanto ampliar } \\
\text { os já abordados. A identificação de aplicações } \\
\text { pedagógicas permite a professores de licenciaturas } \\
\text { debater tais inovações nos cursos de formação inicial } \\
\text { de professores. Também permite a professores de } \\
\text { Artes Visuais de escolas de educação básica conhecer } \\
\text { e eventualmente replicar as práticas pedagógicas } \\
\text { identificadas. No escopo da pesquisa proposta } \\
\text { permite verificar se conceitualmente a questão da } \\
\text { autoria é tratada, se aplicações desenvolvidas } \\
\text { propiciam autoria, se estratégias pedagógicas são } \\
\text { voltadas para o protagonismo e autoria. }\end{array}$ \\
\hline QP3 & $\begin{array}{l}\text { Quais os recursos de TIC } \\
\text { presentes nos artigos que } \\
\text { apresentam pesquisas } \\
\text { interdisciplinares de TIC nas } \\
\text { Artes Visuais? }\end{array}$ & $\begin{array}{l}\text { Identificar recursos tecnológicos usados de forma } \\
\text { interdisciplinar nas Artes Visuais permite propor o } \\
\text { uso dos mesmos na formação inicial e continuada de } \\
\text { professores. }\end{array}$ \\
\hline
\end{tabular}

\section{Resultados e discussão}

A pesquisa permitiu encontrar um total de $\mathbf{3 6}$ artigos que se inseriram nos critérios abordando assuntos relacionados a artes visuais (Tabela 2). 
VI Congresso Brasileiro de Informática na Educação (CBIE 2017)

Anais do XXVIII Simpósio Brasileiro de Informática na Educação (SBIE 2017)

Tabela 2: Quantidade de artigos localizados por ano e veículo de publicação

\begin{tabular}{|c|c|c|c|c|c|}
\hline Ano & IETP & RENOTE & RBIE & SBIE & WIE \\
\hline 2009 & 0 & 1 & 0 & 0 & 0 \\
\hline 2010 & 2 & 2 & 0 & 0 & 0 \\
\hline 2011 & 0 & 2 & 0 & 1 & 0 \\
\hline 2012 & 3 & 0 & 0 & 1 & 1 \\
\hline 2013 & 1 & 0 & 0 & 0 & 0 \\
\hline 2014 & 4 & 1 & 0 & 0 & 1 \\
\hline 2015 & 1 & 2 & 0 & 2 & 1 \\
\hline 2016 & 9 & 0 & 0 & 0 & 1 \\
\hline Total & 20 & 8 & 0 & 4 & 4 \\
\hline
\end{tabular}

Na leitura dos artigos verificou-se que oito dos 36 estudos são realizados fora do Brasil, estando todos no mesmo número da revista Informática na Educação: Teoria \& Prática (2016). Foram, portanto, excluídos, pois o foco é em pesquisas realizadas no Brasil. A partir do corpus compilado dos artigos restantes, realizou-se uma análise dos registros encontrados, considerando as perguntas norteadoras apresentadas na Tabela 1.

Ainda ressalta-se que a revista RBIE não tem uma única publicação relacionada a artes visuais. Isso tanto pode ser uma demonstração de falta de pesquisas no tema ou de interesse dos pesquisadores da área de Artes em publicar em revistas e eventos de Informática na Educação. Esta segunda hipótese pode ser levada para novo estudo bibliográfico a ser feito em eventos e revistas específicos de artes visuais. Nas subseções a seguir apresentamos algumas análises mais específicas.

\subsection{Ano e local de publicação - tendências}

Contabilizando as menções de cada localidade na afiliação dos autores de cada artigo, criamos um mapa que permite refletir sobre a produção de publicações de Artes Visuais e TIC e onde se concentram estas produções. Percebe-se uma maior concentração da produção acadêmica a respeito do tema nas regiões Sul e Sudeste do país, principalmente no estado do Rio Grande do Sul. A UFRGS, em Porto Alegre, foi o local de onde saíram mais publicações. No estado, as demais cidades e suas respectivas instituições citadas foram: a UFSM em Santa Maria, a UNICRUZ em Cruz Alta e uma menção em Porto Alegre a Rede Gaúcha de Ensino à Distância. Esta última não é em si uma instituição, mas uma rede de instituições, porém respeitou-se a afiliação indicada. Há também uma concentração de pesquisadores na cidade de Campinas - SP, na UNICAMP, e na cidade do Rio de Janeiro, na UFRJ. São instituições nas quais estudos mais aprofundados sobre essa temática podem buscar subsídios e propor parcerias. 


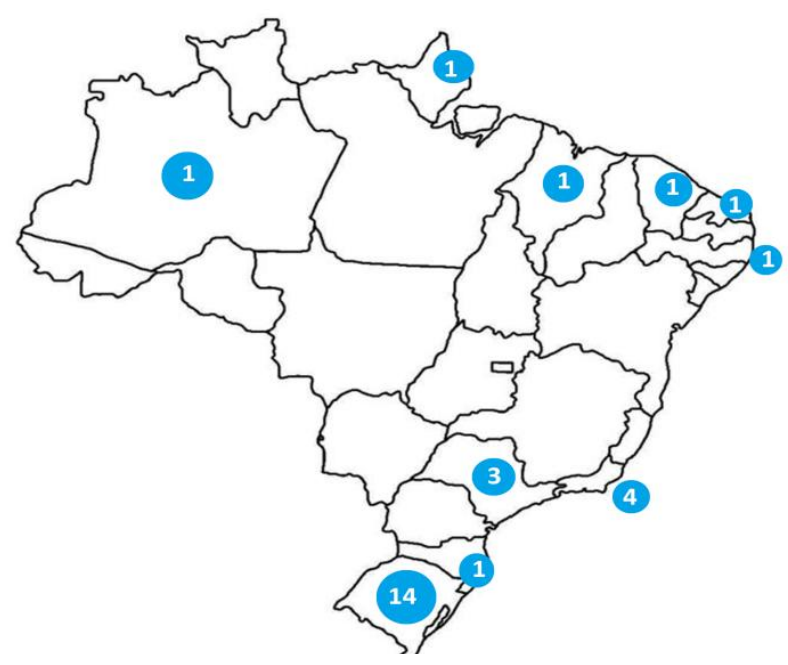

Figura 1. Mapa dos locais de afiliação dos autores das publicações

Quanto ao ano, pode-se observar, conforme a Tabela 2, que 22 dos 36 artigos encontrados inicialmente foram produzidos a partir de 2014. Tal informação pode indicar três coisas. Primeiro, que pesquisadores com afinidade com as Artes Visuais passaram a ter mais interesse nas publicações sobre Informática, o que poderia ser verificado em futura análise de publicações específicas de Artes. Segundo, que está crescendo o incentivo para acadêmicos produzirem e investigarem relações entre os dois campos. Por último, pode estar havendo um aumento na relevância da construção e desenvolvimento desta intersecção estimulando a interdisciplinaridade.

\subsection{Foco do artigo}

Dentre os artigos analisados, identificamos a recorrência de três focos de pesquisa diferentes: i) aplicação pedagógica das ferramentas das artes visuais e tecnologia na educação; ii) desenvolvimento de softwares ou aplicações; e iii) discussões conceituais a respeito de artes e tecnologias.

Quatro dos artigos pesquisados apresentam desenvolvimento de software relacionado a artes para a educação. Destes, três são sobre programas de mediação museológica, sendo um museu virtual (MOURA et al, 2012) e dois sobre o mesmo software de interação, por meio de realidade aumentada, com um museu físico (SILVEIRA; BIAZUS; AXT, 2011). O quarto trata de uma relação entre plantas vivas e máquinas para criação de um artefato artístico (NÓBREGA, 2012).

É interessante analisar nas publicações seu fator interdisciplinar, pois se pode aliar as artes visuais a qualquer outro campo de conhecimento._Estão presentes nos artigos temas diversos como matemática, desenvolvimento de jogos, biologia, política, educação de informática para jovens e adultos, música, teatro, história em quadrinhos.

Dentre os artigos selecionados, dezoito apresentam aplicação pedagógica, tendo sido dois já citados também por apresentarem desenvolvimento de software. A faixa etária do público dos estudos é bastante variável. Aparecem ações pedagógicas com alunos da EJA do Ensino Médio, Ensino Médio regular, Ensino Fundamental regular e Ensino Superior. Além de escolas e universidades, houve artigos que relataram trabalho com formação de professores, crianças em atendimento terapêutico e público visitante de museus. Ressaltamos que "fluência" tecnológica não se associa apenas a idade (e esta 
VI Congresso Brasileiro de Informática na Educação (CBIE 2017)

Anais do XXVIII Simpósio Brasileiro de Informática na Educação (SBIE 2017)

ao segmento escolar), mas que depende de fatores como região, classe social e esfera das escolas (públicas ou privadas).

Sobre as discussões conceituais, identificamos serem o foco de oito artigos. Nem todos abordam questões literalmente relacionadas a tecnologias digitais, porém trazem questões do mundo contemporâneo que podem contribuir significativamente para a construção de relações entre ela e as artes. Um deles trata do uso do espaço urbano a partir de performances artísticas em locais banais e cotidianos, criando situações de estranheza e curiosidade entre os espectadores (BOM-TEMPO, 2014). Outro trata de reflexões sobre a criação de possíveis recursos para melhorar a experiência de visitação a museus para o público de pessoas cegas (KASTRUP, 2010).

\subsection{Softwares e serviços utilizados}

Houve uma grande variedade de softwares e ferramentas utilizadas e/ou mencionadas para a utilização pelos alunos nas pesquisas levantadas. Destaque-se esta variedade como uma forma de demonstração do uso das artes visuais com variados recursos, com a presença desde linguagens de programação, frameworks de realidade aumentada, editores de imagem, programas de modelagens 3D, criação de colagens, museus virtuais, entre outros.

Três dos artigos relatam o uso do ambiente virtual Moodle para compartilhamento de conhecimento entre as pessoas participantes. Também foram mencionados como utilizados para compartilhamento os sites Vimeo, Youtube e PbWorks. Alguns editores de texto foram utilizados (Word, Writer), bem como editores de apresentação (Power Point, Prezi), de imagens (Sumo Paint, KolourPaint, Hugin, GrafEq), de áudio (Audacity), de gráficos (GraphEquation, GeoGebra) e de jogos/animações (Stencylworks, Scratch, Estúdio Stop Motion, Blender, Voki). Uma proposta a ser considerada como um benefício das artes visuais em conjunto com as TIC na educação é o uso de softwares com possibilidade de serem utilizados profissionalmente pelos alunos. Dentre estes estão Photoshop, Blender, Prezi e a linguagem de programação Java.

Infelizmente a maioria dos estudos que envolviam ações pedagógicas com algum software tinham o foco do seu trabalho nas técnicas e procedimentos. $\mathrm{O}$ pensamento artístico, sensível e a criatividade ficaram, na maior parte dos casos, em segundo plano ou completamente esquecidos.

\section{Considerações finais}

A revisão bibliográfica sobre a integração de TIC com Artes Visuais focado em revistas e anais de eventos de Informática na Educação sugere que a atual produção brasileira de ensino-pesquisa acerca do tema é restrita. O primeiro indicador é a própria quantidade de artigos localizados, o que pode significar que produções desse tema estejam preferencialmente em eventos e revistas específicos de Artes Visuais. Essa hipótese pode ser analisada em outro estudo bibliográfico. Sobre o desenvolvimento de ferramentas e aplicações para uso na educação em artes visuais, o foco parece ser ainda mais restrito, uma vez que apenas 4 artigos foram localizados. Isso sugere pouco desenvolvimento nacional e uso de ferramentas prontas, pois é improvável a publicação de desenvolvimentos específicos dessa área somente em revistas e eventos da área de 
artes visuais. Supõe-se que produções dessa natureza estariam divulgadas em revistas e eventos representativos da comunidade de informática na educação.

Em sua grande maioria, os artigos selecionados não mostram uso das TIC de forma criativa dentro dos conteúdos de Arte. As questões artísticas aparecem muito pouco, ficando mais em evidência os procedimentos técnicos do uso dos softwares e ferramentas mencionados. Mesmo quando há propostas que buscam produção criativa dos participantes, elas são muitas vezes transposições de técnicas que poderiam ser analógicas para o meio digital, como edição de imagens. O potencial incentivo a autoria das TIC atuais e das Artes Visuais tem sido pouco explorado nas pesquisas.

Ressalte-se, porém, não haver demérito nos estudos realizados até o momento, visto que esse tipo de atividade possui suas próprias vantagens, que devem continuar a estimular pesquisa e autoria por parte de alunos. Poderia se propor como enriquecimento o uso de referências de artistas cujo trabalho acontece exclusivamente por meios digitais, por exemplo. Desta forma seria mais efetivo o convite aos alunos de explorar a criação independente, uso das tecnologias como meio de pesquisa para criação artística, interatividade em vídeo, fotografia, projeções, redes sociais.

$\mathrm{O}$ aspecto regional também poderia ser incentivado, buscando o resgate de culturas locais com arte e tecnologia, incentivando mais pesquisas nas regiões Norte e Nordeste e estimulando algum grupo da região Centro-Oeste, ausente completamente nas produções analisadas.

As dificuldades que podem ser apontadas para realizar esse estudo são as limitações dos termos de busca, a existência de muitos artigos sem palavras-chave e a falta de critério, muitas vezes, para escolha das palavras-chave.

As artes visuais são um caminho abrangente e democrático pouco explorado por pesquisadores de informática na educação no Brasil. Apreendidas desde a infância até a idade adulta, podem ser inseridas em qualquer circunstância social e pedagógica, com grande potencial de crescimento cultural e intelectual. Sugere-se, portanto, como trabalhos futuros, um levantamento bibliográfico em publicações de artes visuais, e busca de situações mais criativas e conceituais. Existem muitas possibilidades para as TIC além de serem ferramentas com o mesmo uso costumeiro e óbvio.

\section{Referências bibliográficas}

BARBOSA, Ana Mae (org.). Arte/Educação Contemporânea: consonâncias internacionais, 3 ed. São Paulo: Cortez, 2010.

BOM-TEMPO, Juliana. Rasgos do urbano: imagens em deriva. Informática na Educação: Teoria e prática. Porto Alegre, v. 17, jun 2014.

BRASIL. Parâmetros Curriculares Nacionais (5ª a 8a séries): Arte. Brasília, 1998.

BRASIL. Parte II - Linguagens Códigos e suas Tecnologias. Parâmetros Curriculares Nacionais do Ensino Médio. Brasília, 2000.

CETIC. Pesquisa sobre o uso das Tecnologias de Informação e Comunicação nos domicílios brasileiros - TIC Domicílios 2015. São Paulo, 2016. Disponível em: $<$ http://cetic.br/publicacao/pesquisa-sobre-o-uso-das-tecnologias-de-informacao-ecomunicacao-nos-domicilios-brasileiros-tic-domicilios-2015/>

DELEUZE, Gilles. Bergsonismo. Tradução de Luiz B. Orlandi. São Paulo: ed.34, 1999. 
VI Congresso Brasileiro de Informática na Educação (CBIE 2017)

Anais do XXVIII Simpósio Brasileiro de Informática na Educação (SBIE 2017)

KASTRUP, Virgínia. Experiência Estética para uma Aprendizagem Inventiva: notas sobre a acessibilidade de pessoas cegas a museus. Informática na Educação: Teoria e prática. Porto Alegre, v. 13, dez 2010.

KITCHENHAM, B. Guidelines for Performing Systematic Literature Reviews in Software Engineering" Version 2.3. EBSE Technical Report, UK. 2007.

MARTINS, Alice Fátima. Novas tecnologias e o ensino de artes visuais: algumas considerações, p. 627 - 636. In: Anais do $\mathbf{1 6}^{\circ}$ Encontro Nacional da ANPAP. Sandra Regina Ramalho e Oliveira, Sandra Makowiecky (Org.). Florianópolis: ANPAP, UDESC, 2007. Disponível em: <http://anpap.org.br/anais/2007/2007/artigos/063.pdf>.

MOURA, Íthalo Bruno Grigório et al. Musert: Um Museu Virtual em 3D com Recomendação Personalizada de Conteúdo. XXIII Simpósio Brasileiro de Informática na Educação (SBIE), 2012.

NÓBREGA, Carlos Augusto Moreira da. Plantas, máquinas e interafectividade. Informática na Educação: Teoria e prática. Porto Alegre, v. 15, 2012.

PIMENTEL, Lucia Gouvêa. Novas territorialidades e identidades culturais: o ensino de arte e as tecnologias contemporâneas, p. 765 - 771. In: Anais do 20 Encontro Nacional da ANPAP. Rio de Janeiro: ANPAP, 2011. Disponível em: <http://www.anpap.org.br/anais/2011/pdf/ceav/lucia_gouvea_pimentel.pdf> .

RIBEIRO, Walmeri. Territórios Sensíveis: uma investigação performativa em arte, ciência, tecnologia e natureza. ARS (São Paulo), São Paulo, v. 13, n. 26, p. 204213, 2015 Disponível em: $<$ http://www.scielo.br/scielo.php?script=sci_arttext\&pid=S167853202015000200204\&lang=pt>.

SILVA, Paula Marques da. O Uso da Fotografia como Estratégia Metodológica em Pesquisas com Crianças: uma Revisão de Literatura. Informática na Educação: Teoria \& Prática, Porto Alegre, Rs, v. 19, dez. 2016. Disponível em: <http://seer.ufrgs.br/index.php/InfEducTeoriaPratica/article/view/53792/41094>.

SILVA, Célia Cláudia Ormonde Séves da. O Contributo das TIC no processo ensino/aprendizagem das Artes Visuais. Porto, Pt, mar. 2002. Disponível em: <https://repositorio-aberto.up.pt/handle/10216/11936>.

SILVA, Thiago; MEDEIROS, Tainá J. ; ARANHA, Eduardo H. Jogos digitais para o ensino e aprendizagem de programação: uma revisão sistemática da literatura. XXV Simpósio Brasileiro de Informática na Educação (SBIE), 2014. Disponível em <http://www.br-ie.org/pub/index.php/sbie/article/view/3000>.

SILVEIRA, André Luis Marques; BIAZUS, Maria Cristina V.; AXT, Margarete. Diálogos na Arte: Sistema de Autoria em Realidade Aumentada. XXII Simpósio Brasileiro de Informática na Educação (SBIE), 2011.

SILVEIRA, André Marques; BIAZUS, Maria Cristina V.; AXT, Margarete. Realidade Aumentada no Margs: Impressões de um Experimento. Renote, v. 9, 2011.

ZAMPERETTI, Maristani Polidori; ROSSI, Flávia Denke. Tecnologias e Ensino de Artes Visuais - apontamentos iniciais da pesquisa. Holos, Natal, Rn. v. 31, p.190200, dez. 2015. Disponível em: <http://www2.ifrn.edu.br/ojs/index.php/HOLOS/article/download/2031/1321>. 